\title{
Proceeding
}

Supplementary Issue: Spring Conferences of Sports Science. Costa Blanca Sports Science Events, 14-15 June 2019. Alicante, Spain.

\section{Sports selection in martial arts based on the harmonic stability of results at competitions}

\author{
ROMAN SERGEEVICH NAGOVITSYN ${ }^{1}$, FANAVI HAYBRAHMANOVICH ZEKRIN², TATYANA \\ VLADIMIROVNA FENDEL'3, DMITRY ALEXANDROVICH ZUBKOV²
}

${ }^{1}$ Department of Physical Culture and Life Safety, Glazov State Pedagogical Institute, Glazov, Russian Federation

${ }^{2}$ Department of Theory and Methods of Martial Arts, Tchaikovsky State Institute of Physical Culture, Tchaikovsky, Russian Federation

${ }^{3}$ Department of Tourism and Management, Tchaikovsky State Institute of Physical Culture, Tchaikovsky, Russian Federation

\begin{abstract}
The aim of the study: to develop a new approach to sports selection in martial arts based on the analysis of the harmonic stability of the results of fighters in competitions during a sports career. Study participants: Greco-Roman wrestlers of different qualifications $(n=114)$. Research methods: based on the method of studying sports biographies of athletes, mathematical-statistical data processing was carried out using Student's t-criterion. The arithmetic average and harmonic average performance of each Greco-Roman style athlete of different qualifications. The smaller the deviation of the mean harmonic value from the arithmetic average performance of a fighter, the more stable his competitive result. The results of the study. As a result of the analysis, it was revealed that the higher the qualification of an athlete, the more reliable the nonsignificance of the difference in results between the arithmetic and average harmonic indices during a sports career is revealed. Findings. The proposed in the study a new approach to sports selection based on the analysis of the harmonic stability of the results of wrestlers at competitions allows to reliably identify the prospects of a wrestler. Keywords: Sports selection; Harmonic stability; Greco-Roman wrestling; Competitions.

\section{Cite this article as:}

Nagovitsyn, R.S., Zekrin, F.H., Fendel', T.V., \& Zubkov, D.A. (2019). Sports selection in martial arts based on the harmonic stability of results at competitions. Journal of Human Sport and Exercise, 14(4proc), S867-S876. doi:https://doi.org/10.14198/jhse.2019.14.Proc4.49

Corresponding author. Department of Physical Culture and Life Safety, Glazov State Pedagogical Institute, Glazov, Russian Federation. http://orcid.org/0000-0003-4471-0875

E-mail: gto18@mail.ru

Supplementary Issue: Spring Conferences of Sports Science. Costa Blanca Sports Science Events, 14-15 June 2019. Alicante, Spain.

JOURNAL OF HUMAN SPORT \& EXERCISE ISSN 1988-5202

(c) Faculty of Education. University of Alicante

doi:10.14198/jhse.2019.14.Proc4.49
\end{abstract}




\section{INTRODUCTION}

The process of many years of training in any sport begins with the selection procedure and sports orientation (Barreiros et al., 2014). The problem of sports selection has been developed since the mid-20th century. and still remains relevant (Hartigh et al., 2018). At the same time, there are different, sometimes diametrically opposite, views on its solution (Baker et al., 2018).

It is not easy to recognize the future champion in a young athlete (Johnston et al., 2018). Therefore, the role of the coach is very important, he reveals athletic ability, later turning them into talent (Wiseman et al., 2014). Sports abilities are prerequisites for sports achievements and the possibility of their progressive development (Pappalardo et al., 2017). The most important prerequisites include biological factors (Franchini et al., 2011), genetic advances (Stubbe et al., 2005), physical characteristics, type of nervous activity (Morris, 2000), the level of aerobic capacity, the ratio of fast and slow fibres in skeletal muscles (Couceiro et al., 2016), rates of biological maturation (Pearson et al., 2006). The system of sports selection is necessary for revealing sports abilities of future athletes. The problem of sports selection is one of the central issues in the theory and methodology of sports training and involves a wide range of issues addressed by sports science and practice (Abbott et al., 2005). Its relevance not only does not decrease, but increases with a new force. This is due to the fact that the current practice of selection in sports, according to leading experts (Barreiros \& Fonseca, 2012; Elferink-Gemser et al., 2007), cannot yet be assessed as sufficiently effective and up-to-date (Pinder et al. , 2011; Williams \& Ericsson, 2005).

The complexity of the problem of selection and orientation lies in its versatility. Therefore, it should be noted that this part of the trainer's activity belongs to the field of foresight (Musculus \& Lobinger, 2018), the accuracy of which determines the selection efficiency (Johansson \& Fahlen, 2017; Wiseman et al., 2014). For most sports, test selection batteries have already been developed (Egisdottir et al., 2006; Findlay \& Ste-Marie, 2004; Lyons et al., 2011). Despite this, the problem of sports orientation is not yet fully resolved and requires further reflection both by scientists and practitioners. The problem of selection and orientation of the most talented athletes, as an independent direction, is under constant search, improvement and further development (Baker et al., 2018; Hoare \& Warr, 2000). Scientifically based methods for selecting promising children in sports schools (Coghlan, 2003), as well as predicting their future results, become important stages and an integral part of the system of training athletes from beginners to professionals (Coetzee et al., 2015; Isaev et al., 2016).

The scientific basis for such a task is the search for diagnostic procedures that allow a high probability to predict the level of athletes 'talent for practicing a particular sport, particularly in Greco-Roman wrestling (Isaev et al., 2016; Nagovitsyn et al., 2018). This search for monitoring criteria can actually be carried out by studying the stability of the technical-tactical, physical, and psychological characteristics of an athlete. As well as the stability of his performances at official sports competitions. To study the stability of the characteristics of people involved in sports, perennial experiments on a constant contingent of subjects are used (Abbott et al., 2005; Li et al., 2014; Nagovitsyn et al., 2017). In the course of which they apply analysis of sports career and select sports indicators, achievements in which were stable in youth, junior and youth age (Baker et al., 2018). These studies use correlation analysis to identify the relationship between the subject's achievements at different stages of life (Barreiros et al., 2014; Coetzee et al., 2015). There are very few such long-term studies due to the high dropout rates of sportsmen (Hartigh et al., 2018). Given the difficulty of determining the stability of sports characteristics on the basis of long-term observations, one can recognize as relevant the method of studying sports biographies of athletes of various classes (Lyons et al., 2011). 
Thus, the aim of the study: to develop a new approach to sports selection in martial arts based on an analysis of the harmonic stability of the results of wrestlers in competitions during a sports career.

\section{MATERIAL AND METHODS}

\section{Participants}

Men - Greco-Roman style wrestlers of different qualifications from 25 to 45 years old ( $n=114)$, who completed performances at official competitions, except for competitions of veterans (from 35 years old): athletes who received the title of "International Master of Sports" $(n=8)$, athletes who have achieved the title of "Master of Sports" ( $n=49)$ and "Candidate Master of Sports" $(n=57)$. They have authentically identical average arithmetic results at competitions during their sports career. The athletes participating in the experiment consisted of various schools of the Greco-Roman wrestling of the Russian Federation: "Perm Bears", city Perm; "Institute", city Naberezhnye Chelny (Republic of Tatarstan); "School of Higher Sports -Vyatka", city Kirov; "Sports School", city Bor (Nizhny Novgorod Region); "Progress", city Glazov (Udmurt Republic). To participate in the experiment were selected respondents who have a prize in any official competition. They issued an agreement and filled out a diagnostic card: the results of participation in official competitions.

\section{Research methods}

Based on the method of studying sports biographies of athletes, mathematical-statistical data processing was implemented. The arithmetic average and harmonic average performance of each Greco-Roman style athlete of different qualifications is calculated. The first indicator showed the average performance of an athlete for each level of official competitions, in turn, the second - the stability of the wrestler's performance at competitions on the key principle "Stability is a sign of skill".

The arithmetic average of performance at competitions was calculated using the following formulas: $X$ arithmetic $=(x 1+x 2+\ldots+x n) / n ; X$ harmonic $=n /(1 / x 1+1 / x 2+\ldots+1 / x n)$.

The smaller the deviation or the numerical value of the average harmonic from the arithmetic average of the performance of a fighter, the more stable his competitive result during a certain stage.

\section{Organization of the study}

The athletes participating in the experiment were asked to fill out a diagnostic card in which it was necessary to indicate individually obtained places (from first to tenth) in official competitions for their past sports career in levels:

1. Primacy of the city, district or youth sports school;

2. Championship of the region, republic, Russian tournament;

3. Russian official tournament for the award of the title "Master of Sports";

4. Championship of the Federal District of the Russian Federation;

5. Championship of the Russian Federation, International official tournament for the award of the title "International Master of Sports".

Athletes filled the highest of the places reached at the competition, at least seven for each level of official competitions. The missing materials were studied from archival materials, from the Greco-Roman wrestling schools presented above. 


\section{Statistical analysis}

Mathematically-statistical data processing was performed using the Student's t-test at $p=0.05$, taking into account the normal distribution of the sample. Mathematical-statistical processing was carried out between the arithmetic and harmonic averages of performance of athletes of the Greco-Roman style of different qualifications for each level.

\section{RESULTS}

As a result of mathematical-statistical analysis, it was revealed that the athletes "International Master of Sports" $(n=7)$ according to the Student's T-test with $p>0.05$ revealed no uncertainty of the difference in results between the arithmetic and harmonic averages. Only one athlete $(n=1)$, recorded statistical accuracy. What, in turn, means the stability of performance at competitions during the sporting career of the presented sample in Table 1.

Table 1. Results of performance analysis at level wrestler competitions "International Master of Sports"

\begin{tabular}{ccccccc}
\hline Wrestlers / Levels & 1 & 2 & 3 & 4 & 5 & Student's t-test \\
\hline 1. IMS & $1.29 / 1.17$ & $1.86 / 1.5$ & $2 / 1.53$ & $1.86 / 1.5$ & $3.14 / 2.41$ & $\mathrm{p}>0.05$ \\
2. IMS & $2 / 1.68$ & $2.14 / 1.54$ & $2.86 / 2.15$ & $4 / 3.22$ & $4.43 / 3.59$ & $\mathrm{p}>0.05$ \\
3. IMS & $2.57 / 1.85$ & $4.14 / 3.54$ & $3 / 1.71$ & $4 / 2.33$ & $4.86 / 2.98$ & $\mathrm{p}>0.05$ \\
4. IMS & $2.57 / 1.85$ & $3.71 / 2.11$ & $3.57 / 2.13$ & $5.86 / 3.66$ & $5.86 / 3.21$ & $\mathrm{p}>0.05$ \\
5. IMS & $2.43 / 1.58$ & $4.71 / 2.94$ & $5 / 2.42$ & $5.71 / 3.43$ & $6.43 / 3.54$ & $\mathrm{p}<0.05$ \\
6. IMS & $2.57 / 1.85$ & $2.71 / 1.89$ & $4.43 / 2.35$ & $3.57 / 3.5$ & $3.57 / 3.31$ & $\mathrm{p}>0.05$ \\
7. IMS & $2 / 1.4$ & $2.43 / 1.81$ & $3 / 2.9$ & $3 / 2.33$ & $6.14 / 3.48$ & $\mathrm{p}>0.05$ \\
8. IMS & $2.43 / 2.1$ & $4.14 / 3$ & $3.71 / 3.59$ & $5.43 / 5.25$ & $6.57 / 3.81$ & $\mathrm{p}>0.05$ \\
\hline
\end{tabular}

*X arithmetic / X harmonic; IMS - International Master of Sports

For further analysis, we studied the diagnostic card performance athletes qualifying level "Master of Sports" And for the demonstration, we selected only those athletes $(n=9)$ who took part in the competition of all five levels at least seven times. Which ranked from first to tenth place in Table 2.

Table 2. Results of performance analysis at level wrestler competitions "Master of Sports"

\begin{tabular}{ccccccc}
\hline $\begin{array}{c}\text { Wrestlers I } \\
\text { Levels }\end{array}$ & 1 & 2 & 3 & 4 & 5 & Student's t-test \\
\hline 1. MS & $2.29 / 1.79$ & $2 / 1.53$ & $2.43 / 1.83$ & $4.71 / 4.11$ & $4.71 / 3.59$ & $\mathrm{p}>0.05$ \\
2. MS & $1.57 / 1.4$ & $2.43 / 1.77$ & $3 / 1.91$ & $5 / 4.54$ & $5 / 4.72$ & $\mathrm{p}>0.05$ \\
3. MS & $2.43 / 1.83$ & $2.71 / 1.51$ & $4.29 / 1.93$ & $3.57 / 2.71$ & $3.43 / 2.17$ & $\mathrm{p}<0.05$ \\
4. MS & $2.14 / 1.75$ & $2.71 / 1.94$ & $2.43 / 2.33$ & $4.14 / 3.65$ & $5 / 3.62$ & $\mathrm{p}>0.05$ \\
5. MS & $2.43 / 2.04$ & $4.43 / 1.96$ & $4.43 / 2.26$ & $4.14 / 2.23$ & $5 / 3.59$ & $\mathrm{p}<0.05$ \\
6. MS & $2.14 / 1.58$ & $3.86 / 2.24$ & $3.57 / 2.16$ & $6.14 / 5.66$ & $6.29 / 5.87$ & $\mathrm{p}>0.05$ \\
$7 . \mathrm{MS}$ & $2.71 / 1.89$ & $3.29 / 2.3$ & $4 / 2.73$ & $5.86 / 5.27$ & $6.14 / 5.81$ & $\mathrm{p}>0.05$ \\
8. MS & $2.71 / 1.94$ & $2.57 / 1.83$ & $4.43 / 3.01$ & $6 / 4.56$ & $7.29 / 7.07$ & $\mathrm{p}>0.05$ \\
$8 . \mathrm{MS}$ & $3.14 / 2$ & $4 / 2.29$ & $4.29 / 3.7$ & $5.71 / 5.12$ & $6.14 / 5.83$ & $\mathrm{p}>0.05$ \\
\hline \multicolumn{7}{c}{ *Xarithmetic/X harmonic; MS - Master of Sports }
\end{tabular}

As a result of the mathematical-statistical analysis, it was found that among athletes of the "Master of Sports" qualification ( $n=7)$, according to the Student's T-test, for $p>0.05$, the uncertainty of the difference in results 
between arithmetic and harmonic averages prevails. However, two athletes $(n=2)$ of this category, recorded statistical significance. Which, in turn, also generally means the stability of performance at competitions during the sports career of the majority of respondents of this target group.

For further analysis, we studied the diagnostic card performance athletes qualifying level "Candidate Master of Sports." And for the demonstration, we selected only those athletes $(n=5)$ who took part in the competition of all five levels at least seven times. On which they ranked from first to tenth place in Table 3:

Table 3. The results of the performance analysis at the competitions of wrestlers of the "Candidate Master of Sports"

\begin{tabular}{lcccccc}
$\begin{array}{c}\text { Wrestlers / } \\
\text { Levels }\end{array}$ & 1 & 2 & 3 & 4 & 5 & Student's t-test \\
\hline 1. IMS & $2.29 / 1.79$ & $4.57 / 1.96$ & $5 / 3$ & $4.14 / 2.23$ & $4.71 / 3.89$ & $p<0.05$ \\
2. IMS & $2.14 / 1.29$ & $4.71 / 2.94$ & $6 / 3.56$ & $5.83 / 3.51$ & $6.13 / 3.24$ & $p<0.05$ \\
3. IMS & $2.43 / 1.58$ & $4.89 / 2.94$ & $7.22 / 3.86$ & $5.71 / 3.43$ & $6.43 / 3.54$ & $p<0.05$ \\
4. IMS & $1.87 / 1.28$ & $3.57 / 1.66$ & $6.38 / 3.16$ & $5.64 / 2.95$ & $7.11 / 3.24$ & $p<0.05$ \\
8. IMS & $1.96 / 1.38$ & $4.43 / 1.96$ & $4.22 / 2.26$ & $5.78 / 3.37$ & $6.87 / 3.45$ & $p<0.05$ \\
\hline \multicolumn{7}{c}{${ }^{*}$ X arithmetic /X harmonic; CMS - Candidate Master of Sports }
\end{tabular}

As a result of the mathematical-statistical analysis, it was revealed that the athletes of the " Candidate Master of Sports" qualification ( $n=5$ ) according to the Student's T-criterion with $p<0.05$ revealed a significant difference in the result indicators between arithmetic averages and harmonic averages. That, in turn, shows the fact of instability of the performance of the participants in this focus group at competitions during a sports career.

For further analysis, we studied the average arithmetic and average harmonic indices for each focus group separately: "International Master of Sports" ( $n=8$ ), "Master of Sports" - 1 ( $n=9)$, "Master of Sports" - 2 ( $n=49$ ), "Candidate Master of Sports" - 1 ( $n=5)$, "Candidate Master of Sports" - 2 ( $n=57)$ in Table 4:

Table 4. Results of an analysis of the average performance at competitions of all wrestlers

\begin{tabular}{lcccccc}
\hline $\begin{array}{c}\text { Wrestlers } \\
\text { Levels }\end{array}$ & 1 & 2 & 3 & 4 & 5 & Student's t-test \\
\hline 1. IMS & $2.23 / 1.69$ & $3.23 / 2.29$ & $3.45 / 2.35$ & $4.18 / 3.15$ & $5.13 / 3.29$ & $\mathrm{p}>0.05$ \\
2. MS-1 & $2.4 / 1.8$ & $3.1 / 1.93$ & $3.65 / 2.43$ & $5.03 / 4.21$ & $5.44 / 4.67$ & $\mathrm{p}>0.05$ \\
3. MS-2 & $2.57 / 1.85$ & $4.31 / 2.54$ & $4.16 / 2.87$ & $4.04 / 2.36$ & $5.11 / 3.97$ & $\mathrm{p}<0.05$ \\
4. CMS-1 & $2.14 / 1.47$ & $4.43 / 2.3$ & $5.77 / 3.17$ & $5.42 / 3.1$ & $6.25 / 3.47$ & $\mathrm{p}<0.05$ \\
5. CMS-2 & $2.28 / 1.52$ & $5.13 / 2.88$ & $6.12 / 4.16$ & $6.11 / 3.37$ & $6.89 / 3.68$ & $\mathrm{p}<0.05$ \\
\hline
\end{tabular}

${ }^{*} X$ arithmetic / X harmonic; IMS - International Master of Sports; MS - Master of Sports (1 - athletes who took part in competitions of all five levels at least seven times; 2 - the remaining wrestlers of this qualification); CMS - Candidate Master of Sports (1 athletes who took part in competitions of all five levels at least seven times; 2 - other wrestlers of this qualification).

As a result of the mathematical-statistical analysis, the same results were found among the athletes "International Master of Sports" qualifications and the focus of the "Master of Russia" - 1. On average, the groups did not identify the difference in results between arithmetic means and harmonic averages. However, the average for the "Master of Sports" - $2(n=49)$ and for both the "Candidate Master of Sports" focus groups, the Student's T-test at $p<0.05$ revealed the accuracy of the results between arithmetic means and harmonic 
averages. That, in turn, proves that the proposed statistical analysis reliably shows the correlation between the wrestler's qualification level and the result stability indicator at competitions.

In turn, the mathematical-statistical processing with $p>0.05$ only the arithmetic means of all focus groups showed no confidence in the differences. What does not show the effectiveness of sports selection only in terms of the indicator - the arithmetic average.

Thus, as a result of the analysis, it was revealed that the Russian wrestlers of the highest international and Russian qualifications, on average, found that the difference in results between the proposed indicators was not reliable. However, on average, in the group of wrestlers of regional low qualifications, the reliability of differences in results was revealed. This proves that the proposed in the study of a new approach to sports selection in martial arts can reliably predict the subsequent effectiveness and prospects of a fighter.

\section{DISCUSSION}

In general, the results of the study are consistent with the results of other studies on the theoretical basis and prognostic validity of sports selection procedures (Coetzee et al., 2015; Hartigh et al., 2018). The implementation of the selection in sports, taking into account the fact that we know from the scientific literature to determine the prospects of an athlete is divided into five main areas.

In scientific studies that experimentally substantiate the need to apply sports selection at the genetic or physiological level (Coghlan, 2003), an original method is proposed. During molecular testing, an attempt was made to predict results in certain sports (Stubbe et al., 2005). The predictability of physiological testing and the role of maturation in the identification of talents in team and personal sports of adolescents are experimentally substantiated (Franchini et al., 2011; Pearson et al., 2006). This philosophy leads to the statement that elite athletes are born and that sports success is already provided for them (Coghlan, 2003). However, the results of our research prove that among talented athletes appropriate statistical selection is necessary.

Psychological direction (Gould et al., 2002; Williams \& Ward, 2007) is based on experimental evidence of the reliability of psychological testing in selecting athletes for a sports team (Morris, 2000). Researchers have shown the need for head coaches to take into account the psychological predisposition of athletes, their emotional compatibility in a team (Grove et al., 2000). Namely, sports psychologists should help clubs and coaches in improving the diagnosis of the psychological characteristics of talented athletes (Musculus \& Lobinger, 2018). In turn, the results of our research complement this theory. Only a psychologically trained athlete can consistently perform at an individual level in competitions throughout a sporting career.

The expert or technical-tactical method (Hoare \& Warr, 2000; Williams \& Ericsson, 2005) focuses on the selection of athletes based on structured interviews with elite trainers or selectors (Johansson \& Fahlén, 2017). However, experimental studies mostly reveal a discrepancy between expert assessments of coaches or scouts for video analysis of applicants for inclusion in national teams (Wiseman et al., 2014). Expert assessments may also be ineffective in sports breeding due to the possible bias of scouts in athletes' different levels of reputation (Findlay \& Ste-Marie, 2004). Researchers propose special technical-tactical diagnostics (Hoare \& Warr, 2000) and tests aimed at testing individual key skills in a particular sport (Couceiro et al., 2016; Krikuha \& Shevtsov, 2012). In unison, our experiment proves that a stable result of an athlete is a high technical and tactical skill. Which is not dependent on the age category and on the constantly changing international rules of the competition in Greco-Roman wrestling. 
The following method, like sports selection according to the latest results in competitions (Elferink-Gemser et al., 2007; Koz et al., 2012; Li, et al., 2014), can be effective in implementing breeding in a relatively short time. However, experimental studies of success in playing hockey (Elferink-Gemser et al., 2007), in football (Mclntosh et al., 2018), wrestling (Coetzee et al., 2015; Kajmovic et al., 2014) show significantly significant ambiguity in the results of identifying promising future athletes. Current high scores in competitions are not necessarily indicative of future potential or "talent" (Barreiros et al., 2014). The last statement is confirmed by our experiment. Realization of sports selection only by the arithmetic average, especially in the last competitions, is not reliably effective.

The historical approach is effective in the long term in the selection of athletes (Abbott et al., 2005). Based on the example of the National Football League, based on a detailed study of past sports results of the focus group, a plan of prospects for individual athletes is built (Lyons et al., 2011). The reliability of this method is experimentally proved by analysing the study of the sports career of individual athletes (Pappalardo et al., 2017). This approach often leads to predictions of greater efficiency through taking samples of athletes' performances at various competitions during his personal sports career (Egisdóttir et al., 2006). However, there is experimental evidence (Baker et al., 2018) that the implementation of sports selection only by counting the average results of athletes during a career cannot be reliable. With an increase in the timing of forecasting, the accuracy of forecasts will significantly decrease, which causes obvious concern about the selection of talents in childhood or in early adolescence (Baker et al., 2018).

Agreeing with the relevance of the method of studying athletes' sports career, in particular, in martial arts (Isaev et al., 2016; Karetos et al., 2016), we note that our study does not contradict these trends. The results of the experiment offer a new look at sports selection. The positions of the work offer an accessible and open mathematical-statistical method in the implementation of sports selection. The choice of athletes is crucial for many sports clubs and organizations, but the empirical and mathematical statistical foundations have received insufficient attention from researchers. In turn, in our study, we discussed the relevant knowledge in the field of sports breeding statistics and combined this knowledge with the theory and practice of sports selection.

\section{CONCLUSIONS}

Thus, the proposed in the study of a new approach to sports selection in martial arts can reliably identify the subsequent effectiveness and prospects of a fighter. Reliably shows the correlation between the increase in sports qualification of a fighter and numerical data of the difference between the arithmetic average and the average harmonic index of performance. Through the analysis of the challenger wrestler's sports seats achieved at competitions at various levels, including in the team and further mathematical processing of the results. The implementation of sports selection according to the proposed mathematical-statistical method will allow to implement the following conditions necessary for the selection:

1. General publicity for all interested parties and openness of statistical criteria for qualification selection. Openness contributes to the purposeful work of the coach and athlete to prevent unfair competition among athletes. Who are actively applying for a place in the composition of candidates for the national team at various levels?

2. Ensuring equal opportunities for all applicants for the title of candidates for the national team at all levels of a sports career. 
3. Motivation of athletes to achieve high results. The presented system of sports selection is designed so that the athlete strives to show the highest, stable sports results. And not only in the key competitions of the Olympic training cycle, but also in various wrestling tournaments.

4. Stability as the main criterion for the skill of a Greco-Roman wrestler. First of all, this is a stable level of sporting achievements and stable qualification growth, taking into account changes in international rules of wrestling.

\section{REFERENCES}

Abbott, A., Button, C., Pepping, G. J., \& Collins, D. (2005). Unnatural selection: Talent identification and development in sport. Nonlinear Dynamics, Psychology, and Life Sciences, 9, 61-88.

Baker, J., Schorer, J., \& Wattie, N. (2018). Compromising talent: Issues in identifying and selecting talent in sport. Quest, 70(1), 48-63. https://doi.org/10.1080/00336297.2017.1333438

Barreiros, A.N, Côté, J., \& Fonseca, A. M. (2014). From early to adult sport success: Analysing athletes' progression in national squads. European Journal of Sport Science, 14(1), 178-182. https://doi.org/10.1080/17461391.2012.671368

Barreiros, A.N., \& Fonseca, A.M. (2012). A retrospective analysis of Portuguese elite athletes' involvement in international competitions. International Journal of Sport Science and Coaching, 7, 593-600. https://doi.org/10.1260/1747-9541.7.3.593

Coetzee, N., Balyi, I., Vardhan, D., \& Putter, W. (2015). Wrestling A Sport for Life. A Long Term Participant Development Guide. https://www.sascoc.co.za/wp-content/uploads/2013/08/LTPD-planSA-Wresling-Federation-31-January-2013.pdf

Coghlan, A. (2003). Elite athletes born to run. New Scientist, 30, 4-5.

Couceiro, M.S., Dias, G., Araújo, D., \& Davids, K. (2016). The Arcane project: How an ecological dynamics framework can enhance performance assessment and prediction in football. Sports Medicine, 46, 1781-1786. https://doi.org/10.1007/s40279-016-0549-2

Egisdóttir, S., White, M. J., Spengler, P. M., Maugherman, A. S., Anderson, L. A., Cook, G., \& Rush, J. D. (2006). The meta-analysis of clinical judgment project: Fifty-six years of accumulated research on clinical versus statistical prediction. The Counseling Psychologist, 34, 341-382. https://doi.org/10.1177/0011000005285875

Elferink-Gemser, M.T., Visscher, C, Lemmink, K.A., Mulder, T. (2007). Multidimensional performance characteristics and standard of performance in talented youth field hockey players: a longitudinal study. J Sports Sci, 25 (4), 481-489. https://doi.org/10.1080/02640410600719945

Findlay, L.C., \& Ste-Marie, D.M. (2004). A reputation bias in figure skating judging. Journal of Sport and Exercise Psychology, 26, 154-166. https://doi.org/10.1123/jsep.26.1.154

Franchini, E., Vecchio, F. D., \& Matsushigue, K. (2011). Physiological profiles of elite judo athletes. Sports Medicine, 41(2), 147-166. https://doi.org/10.2165/11538580-000000000-00000

Gould, D., Dieffenbach, K., \& Moffett, A. (2002). Psychological characteristics and their development in

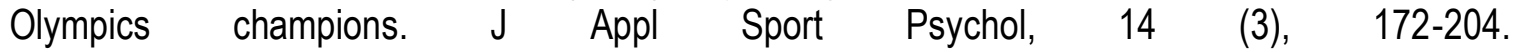
https://doi.org/10.1080/10413200290103482

Grove, W.M., Zald, D.H., Lebow, B.S., Snitz, B.E., \& Nelson, C. (2000). Clinical versus mechanical prediction: A meta-analysis. Psychological Assessment, 12, 19-30. https://doi.org/10.1037//10403590.12.1.19

Hartigh, R.J., Niessen, A.S., Frencken, W.G., \& Meijer, R.R. (2018). Selection procedures in sports: Improving predictions of athletes' future performance, European Journal of Sport Science, 18(9), 1191-1198. https://doi.org/10.1080/17461391.2018.1480662 
Hoare, D.G., \& Warr, C.R. (2000). Talent identification and women's soccer: an Australian experience. J Sports Sci, 18, 751-758. https://doi.org/10.1080/02640410050120122

Isaev, A.V., Korshunov, A.V., Leonov, S.V., Sanoyan, T.R., \& Veraksa, A.N. (2016). Quantitative and Qualitative Indicators of Developing Anticipation Skills in Junior Wrestling Athletes. Procedia - Social and Behavioral Sciences, 233, 186-191. https://doi.org/10.1016/..sbspro.2016.10.191

Johansson, A., \& Fahlén, J. (2017). Simply the best, better than all the rest? Validity issues in selections in elite sport. International Journal of Sports Science \& Coaching, 12(4), 470-480. https://doi.org/10.1177/1747954117718020

Johnston, K., Wattie, N., Schorer, J., \& Baker, J. (2018). Talent Identification in Sport: A Systematic Review. Sports Med, 48(1), 97-109. https://doi.org/10.1007/s40279-017-0803-2

Kajmovic, H., Kapur, A., Radjo, I., \& Mekic, A. (2014). Differences in Performance Between Winners and Defeated Wrestlers in the European Championships for Cadets. International Journal of Performance Analysis in Sport, 14(1), 252-261. https://doi.org/10.1080/24748668.2014.11868719

Karetos, S., Gargalianos, D., Kotsolakis, M., \& Albanidis E. (2014). Selection criteria for the Greek athletes who participated in the Athens 2004 Olympic Games. Journal of Physical Education and Sport, 14(3), 342-350. https://doi.org/10.7752/jpes.2014.03052

Koz, D., Fraser-Thomas, J., \& Baker, J. (2012). Accuracy of professional sports drafts in predicting career potential. Scandinavian Journal of Medicine and Science in Sports, 22, 64-69. https://doi.org/10.1111/j.1600-0838.2011.01408.x

Krikuha, Y.Y., \& Shevtsov, A.V. (2012), Types of Different Techno-Tactical Tie-Ups Used for Control in Greco-Roman Wrestling. Journal International Journal of Wrestling Science, 2(1), 83-89. https://doi.org/10.1080/21615667.2012.10878948

Li, C., Wang, C. J., \& Pyun, D. Y. (2014). Talent development environmental factors in sport: A review and taxonomic classification. Quest, 66, 433-447. https://doi.org/10.1080/00336297.2014.944715

Lyons, B.D., Hoffman, B.J., Michel, J.W., \& Williams, K.J. (2011). On the predictive efficiency of past performance and physical ability: The case of the National Football League. Human Performance, 24, 158-172. https://doi.org/10.1080/08959285.2011.555218

McIntosh, S., Kovalchik, S., \& Robertson, S. (2018). Validation of the Australian Football League Player ratings. International Journal of Sports Science \& Coaching, 13(6), 1064-1071. https://doi.org/10.1177/1747954118758000

Morris, T. (2000). Psychological characteristics and talent identification in soccer. J Sports Sci, 18 (9), 715-726. https://doi.org/10.1080/02640410050120096

Musculus, L., \& Lobinger, B.H. (2018). Psychological characteristics in talented soccer players recommendations on how to improve coaches' assessment. Frontiers in Psychology, 9, 395. https://doi.org/10.3389/fpsyg.2018.00041

Nagovitsyn, R. S., Volkov, P. B., Miroshnichenko, A. A., Tutolmin, A. A., \& Senator, S. Yu. (2017). The influence of special graduated weight load in Greco-Roman wrestling on the growth of students' sports results. Physical education of students. 21(6), 294-301. https://doi.org/10.15561/20755279.2017.0606

Nagovitsyn, R.S., Zhuikova, S.E., Kondratiev, N.V., Osipov, A.Y., Zhavner, T., \& Vapaeva, A. (2018). Influence of sports asymmetry and ambidexterity of ground wrestling on the level of competitive performance of Greco-Roman style wrestlers. Journal of Physical Education and Sport. 18(4), 24722477. https://doi.org/10.7752/jpes.2018.04370

Pappalardo, L., Cintia, P., Pedreschi, D., Giannotti, F., \& Barabasi, A. L. (2017). Human perception of performance. ArXiv preprint arXiv, 1712, 02224. 
Pearson, D.T., Naughton, G. A., \& Torode, M. (2006). Predictability of physiological testing and the role of maturation in talent identification for adolescent team sports. Journal of Science and Medicine in Sport, 9, 277-287. https://doi.org/10.1016/j.jsams.2006.05.020

Pinder, R. A., Davids, K., Renshaw, I., \& Araújo, D. (2011). Representative learning design and functionality of research and practice in sport. Journal of Sport and Exercise Psychology, 33, 146155. https://doi.org/10.1123/jsep.33.1.146

Stubbe, J.H., Boomsma, D.L., \& Geus, E.J. (2005). Sport participation during adolescence: a shift from environmental to genetic factors. Med Sci Sports Exerc; 37: 563-570. https://doi.org/10.1249/01.mss.0000158181.75442.8b

Williams, A.M., Ericsson, K.A. (2005). Perceptual-cognitive expertise in sport: some considerations when applying the expert performance approach. Hum Move Sci, 24, 283-307. https://doi.org/10.1016/j.humov.2005.06.002

Williams, A.M., Ward, P. (2007). Perceptual-cognitive expertise in sport: exploring new horizons. In: Tenenbaum G, Eklund R, editors. Handbook of sport psychology. 3rd ed. New York: John Wiley \& Sons, 203-223. https://doi.org/10.1002/9781118270011.ch9

Wiseman, A.C., Bracken, N., Horton, S., \& Weir, P. L. (2014). The Difficulty of Talent Identification: Inconsistency among Coaches through Skill-Based Assessment of Youth Hockey Players. International Journal of Sports Science \& Coaching. 9(3), 447-455. https://doi.org/10.1260/1747$\underline{9541.9 .3 .447}$

\section{(9) $(\Theta \Theta \Theta$}

This work is licensed under a Attribution-NonCommercial-NoDerivatives 4.0 International (CC BY-NC-ND 4.0). 